\title{
Book Review - The Perfect Online Course: Best Practices for Designing and Teaching
}

Editors: Orellana, A., Hudgins, T. L., \& Simonson, M. (2009). Charlotte, NC: IAP - Information Age Publishing, Inc. ISBN: 978-1-60752-120-4.

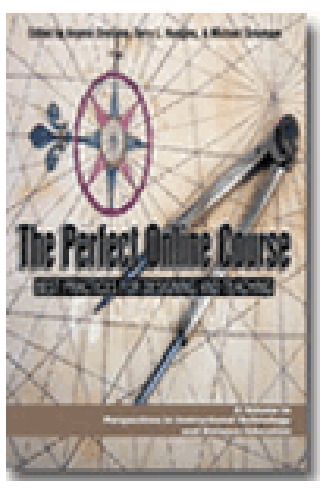

Reviewer: Marta Ruiz-Corbella, Universidad Nacional de Educación a Distancia (UNED), Spain

Presenting a book on the perfect online course might seem a little pretentious. The editors are well aware that there is no such thing as the perfect course, despite stating it in the title. They are not trying to hoodwink the reader with foolproof formulas, and they say so. They admit that the perfect online course is "a pipe dream" (p. 10), but they also argue that it is possible to get close to this perfection. This is the starting point for an understanding of the book's content, its structure, the choice of topics and research work presented, and the valuable contributions made by experts, all of which contribute to the diversity and wealth of content to be found by the reader.

The first thing the editors make clear is that for an online course to be excellent, it must follow a design guided by quality standards. Only then can we talk about a good online course. But why is this book interesting and timely? We could argue that it is merely one more text published in response to the trend toward delivering online courses. Certainly, the surge in e-learning cannot be ignored. But this is more than just a craze; we are seeing an overwhelming change that is shaking up all institutions involved in training. The massive impact of information and communication technology has brought radical change to education, opening up new possibilities and platforms for every imaginable course design. A telling fact is that within the past five years, all universities have started to offer part of their courses and/or study programmes online (p. 327). Faced with this transformation of learning environments, the authors first reflect on what an online training course design is, what it really involves, and then collect experiences and examples of good practices for those elements that are present in all designs. 
Of course, they do not set out to provide a design that is valid for every course as this would be a contradiction. While acknowledging the limitations of a book, what they do propose is to analyse key emerging issues in distance learning and in the design of quality online programmes and courses.

The second point the editors stress is that when we are talking about good practice in designing distance learning and/or online courses, it is vital to clarify exactly what each of them is (p. x), although both terms are used indiscriminately throughout the book. This makes clear that course design for distance or online learning is radically different from that for face-to-face learning. The editors emphasise that distance learning is a methodology in which all components must be designed to achieve their objectives, taking into account the environment and context in which it takes place. (p. 5). This principle, although it may appear obvious, is forgotten in many teaching courses, and this invariably leads to failure. This omission is particularly common in educational experiences based on the increased use of technology. Nobody questions the fact that ICT has revolutionised the design of distance learning courses, demanding decisions that fit in with this methodology and particularly with the objectives to be achieved and the context in which they are to be implemented. Technology has been responsible for generating the surge in online courses, and many institutions see this methodology as the future of training-and of their business. However, as this book makes clear, technology in itself does not guarantee better learning (p. 90). Technology should be at the service of distance learning; it should suit the course objectives, the context in which it is being delivered, the target group, and so on. In this vein, the editors insist throughout the book that there is no such thing as a "one size fits all" online training design model and that the perfect course does not exist. What we can determine are key rules that help us to reflect and take our own decisions: the design should suit the institution's own needs and capabilities, and those of the target students; the number of students a course is designed for will affect decisions made about methodology; the technology should be adapted to serve programme objectives and not the other way around; there are no such things as super-technologies, in that all technologies have their pros and cons; the very latest technology is not necessarily better than existing technology; and so on.

The book is organised into four sections. The first focuses on the main features involved in the design of any distance and/or online teaching programme. These issues may seem obvious, but they need to be emphasised repeatedly. This is one of the book's great contributions as it draws together and sets out the basic content for distance learning methodology, without which an online course cannot be understood. Many other studies discuss good practice, online course design, etc., without having first clarified the specific methodology their discussion is based on. This makes it difficult to evaluate what is being put forward or the reason behind each of the methodological decisions taken and even more difficult to transfer it to other contexts. It is worth reading the two chapters in this section carefully as they provide the reader with key and thought-provoking ideas for approaching the design of any online training course.

The second section is comprised of a selection of case studies and research on the best 
procedural standards and guidelines. It deals with a diverse range of contexts, topics, and content, with each chapter contributing data, ideas, and experiences that are bound to be of interest. This varied approach enables readers to pick the chapters that interest them most, according to their needs and preferences. However, it would have been more helpful if real-life experience had been highlighted more than research data. The former describe situations from which to learn. The latter, however interesting, do not always focus on the elements of teaching design that are most in demand and, as the authors themselves point out, are not always widely applicable, making them less useful. It would have been much better to pay closer attention to research outcomes that could be applied to other contexts.

The same can be said for the third and fourth sections, which describe the best models, methods, and teaching strategies. Both tackle different teaching design models, and advantages and drawbacks are compared. Once a model has been chosen, and depending on the context in which online training is to be delivered, a suitable matrix of technology for achieving the course objectives has to be selected. This seems obvious but is in fact one of the most common errors made in any design: not knowing what teaching design is being followed and what each of the decisions demands. The editors are quite right to stress this issue.

Another issue they highlight is assessment, a key part of any training process. Assessment must be logically coherent with respect to all the elements involved in the design and must be applied throughout the whole process, using a range of strategies (p. 312). No type of assessment can be understood without students being given ongoing feedback, enabling them to manage their learning. In this section, it is striking that the editors touch on an issue of great concern to the teaching profession, one that is not tackled often enough in texts of this kind. I am referring to the problem of student dishonesty and the possible fraud that can be committed using this mode of learning. Dishonesty is not a new problem in education, and distance learning is no exception. Indeed, some authors are convinced that the lack of personal contact with students makes fraud much easier. However, the author of this chapter argues (p. 327) that in the majority of cases this issue is not implicit in the methodology but is due to poorly produced or badly monitored course design. He puts forward a series of basic ideas to be applied to any teaching process: coherent teaching design, clear instructions, ongoing interaction with students, setting up continuous assessment in line with course objectives and content, clear feedback, etc., all aimed at reducing the frequency of these dishonest situations. He also argues that we should not be naive and we should be familiar with and know how to use computer software that can detect plagiarism. But, although we should be aware that fraud exists, our top priority is to help students to organise their studies as not all of them want or know how to self-manage their learning process (p. 425). It is not a question of teachers taking on the role of prosecutors of dishonesty but of analysing our course design to find the weak spots that may cause stress in students.

Another promising area tackled by the authors, and one to which teachers and managers do not give sufficient thought, is that when we talk about distance education we are talking about distance teaching and learning. This means that teachers' actions are radically different because they are mostly going to be working with courses that they have not designed 
themselves, handling tools not chosen by them and carrying out processes that they have not specified. On this point, the authors once again stress the importance of teamwork in designing any online course as there are so many different specialists involved that the whole process is very complex.

Another factor is that students are learning at a distance and not all of them are well prepared for the experience. This is why it is vital to work with these students beforehand, as mentioned earlier, or determine at what point we can insist on the importance of self-managed learning and personal responsibility (p. 179). Both of these inevitably entail ongoing interaction between teacher and student/s, the need for technical support, accessible and updated course design in which all the material is available from the outset, being able to read and write in different environments, the ability to search for information, computing skills, etc., without which a distance learning process is unlikely to be successful.

In conclusion, and in the words of the editors, "the perfect online course is a pipe dream . . . so let us be more realistic (and legal). The key to an effective course is the direct, purposeful involvement of a knowledgeable teacher; one with content knowledge, teaching skills and design experience" (p. 550). The effort expended in selecting and compiling the texts included here reflects how vitally important it is that a teacher or manager interested in creating a distance training course has access to the basic content required to design it with some guarantee of quality.

\section{Athabasca University $\mathbf{A}$}

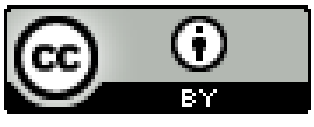

